Copyright by the Ecological Society of America. John D. Willson and William A. Hopkins 2011. Prey morphology constrains the feeding ecology of an aquatic generalist predator. Ecology 92:744-754. http:// dx.doi.org/10.1890/10-0781.1

\title{
Prey morphology constrains the feeding ecology of an aquatic generalist predator
}

\author{
John D. Willson ${ }^{1,3}$ AND William A. Hopkins ${ }^{2}$ \\ ${ }^{1}$ University of Georgia, Savannah River Ecology Laboratory, Drawer E, Aiken, South Carolina 29802 USA \\ ${ }^{2}$ Department of Fisheries and Wildlife Sciences, Virginia Polytechnic Institute and State University, 100 Cheatham Hall, \\ Blacksburg, Virginia 24061 USA
}

\begin{abstract}
Resource availability and accessibility are primary factors guiding the distribution and abundance of organisms. For generalists, prey availability reflects both prey abundance and differences in quality among prey taxa. Although some aspects of prey quality, such as nutritional composition, are well studied, our understanding of how prey morphology contributes to overall prey quality is limited. Because snakes cannot reduce prey size by mastication, many aspects of their feeding ecology (e.g., maximum prey size, feeding performance, and the degree of postprandial locomotor impairment) may be affected by prey shape. We conducted a uniquely comprehensive comparison of prey quality for a generalist species, the banded watersnake (Nerodia fasciata), using prey that were similar in mass and presumably similar in nutritional composition but different in shape and habitat association. Specifically, we compared nutritional composition and shape of paedomorphic salamanders (Ambystoma talpoideum) and sunfish (Lepomis marginatus) and used a series of repeatedmeasures experiments to examine feeding performance (number of prey consumed, maximum prey size, and intra-oral transport time), digestive metabolism (specific dynamic action, SDA), and postprandial locomotor performance of snakes fed Ambystoma and Lepomis. Cost of digestion was similar between the prey types, likely reflecting their similar nutritional composition. However, snakes consumed larger Ambystoma than Lepomis and intra-oral transport time was much shorter for Ambystoma. Snakes fed Lepomis also suffered greater reduction in crawling speed than those fed Ambystoma. These differences highlight the need for behaviorally integrated approaches to understanding prey quality and support field observations of the importance of amphibian prey for juvenile watersnakes.
\end{abstract}

Key words: Ambystoma talpoideum; banded watersnakes; feeding performance; intra-oral transport; Lepomis marginatus; locomotor performance; Nerodia fasciata; prey handling; specific dynamic action.

\section{INTRODUCTION}

Classically, one of the goals of ecology is to understand factors that determine the distribution and abundance of organisms. Among the biotic and abiotic factors that can contribute to the abundance of a species, perhaps none is more obvious than the availability and accessibility of suitable food resources (White 2008). Many studies use abundance (e.g., number or biomass) of potential prey taxa exclusively as an index of habitat suitability. However, even for dietary specialists, a simple measurement of prey abundance fails to provide an adequate assessment of true resource accessibility. For example, habitat structure or complexity can influence prey encounter or capture rates such that foraging success may vary among

Manuscript received 22 April 2010; revised 29 July 2010; accepted 2 August 2010. Corresponding editor: A. M. Bronikowski.

3 Present address: Department of Fisheries and Wildlife Sciences, Virginia Polytechnic Institute and State University, 100 Cheatham Hall, Blacksburg, Virginia 24061 USA.

E-mail:willsonj@vt.edu habitats with similar numerical prey abundances (Crowder and Cooper 1982, Mullin and Cooper 2000). Assessing resource availability and accessibility is further complicated for generalist species because prey taxa may differ in quality. Prey quality represents a measure of the net gain of energy or nutrients, offset by costs, including time and energy expenditure and incurred risk of predation or injury, of prey capture, handling, processing, and digestion. Nutritional composition of prey is easily measured and can have direct effects on a variety of fitness-related traits (Mayntz et al. 2003, Wilder and Rypstra 2008). For example, young Red-legged Kittiwakes (Rissa brevirostris) fed low-lipid diets exhibit reduced growth and impaired learning abilities compared to those reared on high-lipid diets (Kitaysky et al. 2006). Conversely, factors that influence the costs associated with prey quality are complex and often poorly understood. In particular, few studies have examined how prey shape effects the costs incurred during prey capture, handling, and processing (Vincent et al. 2006). 
Snakes provide an excellent opportunity to evaluate the effects of prey shape on various aspects of feeding ecology, physiology, and postprandial locomotor performance. All snakes are obligatory carnivores and typically cannot adjust the size of potential prey by mastication (Arnold 1993). Therefore, relative prey mass and shape ultimately determine both the maximum size of prey that can be consumed and the time and effort expended during consumption (Mori 1991, 1993, 1996, Arnold 1993, Vincent et al. 2006). Moreover, snakes are forced to consume all components of each prey item, regardless of nutritional quality or digestibility. Because snakes lack limbs, they rely solely on their jaws and body musculature for both prey handling and locomotion (Cundall 1987). Therefore, the added burden of a large meal can hinder snake locomotor performance (Garland and Arnold 1983, Ford and Shuttlesworth 1986, Shine and Shetty 2001, Mehta 2006, Mehta and Burghardt 2008). Although the effects of prey size on snake feeding behavior and performance have been examined in several species (e.g., Mori 1991, 1993, 1996, Arnold 1993, Vincent et al. 2006), few studies have compared feeding performance, digestive metabolism, or post-feeding locomotor performance of snakes fed prey that are similar in size but different in shape.

We conducted a uniquely comprehensive evaluation of the effects of prey morphology on feeding ecology in a generalist predator, the banded watersnake (Nerodia fasciata). Specifically, we selected two prey taxa that are similar in mass, abundant, and frequently consumed by watersnakes, paedomorphic salamanders (Ambystoma talpoideum) and centrarchid sunfish (Lepomis marginatus), that are characteristic of fishless and permanent wetlands, respectively (see Appendix). We compared nutritional composition and body shape of each prey type and used a series of repeated-measures experiments to examine feeding performance (number of prey consumed, maximum prey size, and intra-oral transport time), digestive metabolism (specific dynamic action, SDA), and postprandial locomotor performance (maximum crawling speed) of snakes fed Ambystoma and Lepomis. Because Ambystoma are more elongate at a specific body mass and contain fewer impediments to intra-oral transport and digestion (e.g., scales and spiny fin rays), we predicted that snakes would be able to consume more massive Ambystoma than Lepomis and consume Ambystoma more rapidly. Further, we expected that the large amounts of bony material present in Lepomis would result in a higher cost of digestion (SDA response) for Lepomis than Ambystoma. Finally, consumption of fish, which are relatively stiff-bodied, has been shown to impair locomotor performance in snakes (Garland and Arnold 1983). Thus, we expected that consumption of Lepomis would induce greater body distension than consumption of Ambystoma, resulting in reduced maximum crawling speed in snakes that consumed Lepomis compared to those that consumed Ambystoma.

\section{Methods}

\section{Experimental subjects}

The banded watersnake (Nerodia fasciata) is an abundant, moderately large semiaquatic snake that is found in a variety of aquatic habitats throughout its range in the southeastern United States (Gibbons and Dorcas 2004). Nerodia fasciata is generally characterized as an opportunistic feeder and is known to consume a variety of aquatic vertebrate prey, with a particular preference for fish and amphibians (Gibbons and Dorcas 2004). Pregnant female N. fasciata $(n=8)$ were captured in aquatic minnow traps at various uncontaminated aquatic habitats on the U.S. Department of Energy's Savannah River Site (SRS), in South Carolina, USA, and maintained in the laboratory until parturition. Following parturition, neonates $(n=77)$ were maintained communally in $75.7-\mathrm{L}$ aquaria that were lined with paper towels and equipped with large water bowls, hide boxes, and basking lamps (12 L:12 D) to provide thermal gradients within cages. Snakes were offered ad libitum fish or amphibian larvae approximately once per week between experiments. Some snakes exhibited an initial preference for amphibian prey. Thus, to minimize the effects of prior feeding experience on our results, we only included snakes that had previously consumed both prey types in our experiments. In all experiments snakes were randomly assigned to treatments to remove potentially confounding litter effects.

\section{Prey collection, morphology, and nutritional composition}

We selected prey types that are abundant and similar in weight, but very different in morphology: paedomorphic mole salamanders (Ambystoma talpoideum) and dollar sunfish (Lepomis marginatus). Nerodia fasciata feed on both Ambystoma and Lepomis on the SRS (J. Willson and C. T. Winne, Savannah River Ecology Laboratory, unpublished data) and elsewhere (Gibbons and Dorcas 2004). However, these prey types are typical of different habitats used by $N$. fasciata in the Coastal Plain of the southeastern United States (see Appendix); aquatic salamanders are the dominant prey within fishless wetlands (i.e., those that dry periodically and are isolated from permanent water bodies), whereas centrarchid fish are the dominant (by biomass) prey type in more permanent wetland habitats. Prey representing a variety of sizes were collected from uncontaminated aquatic habitats on the SRS using minnow traps. Prey were blotted dry, weighed (nearest $0.01 \mathrm{~g}$ ), and individually frozen for use in subsequent experiments. Offering previously killed prey allowed us to focus on the effects of prey shape on feeding behavior by removing the confounding effects of prey activity or defensive behavior. Body shape of each prey type was assessed by measuring maximum body depth and maximum width (nearest $0.01 \mathrm{~mm}$; measured just anterior to the dorsal fin in Lepomis) for 30 individuals 
of each prey type and testing for differences in maximum dimensions using analysis of covariance (ANCOVA), with prey mass as a covariate. Whole-body prey samples ( $n=4$ per prey type, spanning the mass range used in the digestive metabolism experiment) were dried to constant mass in a freeze drier and analyzed for nutritional composition (protein, lipid, and energy content) at the University of Arkansas's Poultry Science Center, Fayetteville, Arkansas, USA. Although dietary values are reported on a wet mass basis, differences in nutritional content between prey types were examined using ANCOVA with absolute protein and lipid content, dry mass, and energy content $(\mathrm{kJ})$ as dependent variables and prey wet mass as the covariate. In all experiments, prey rations were determined based upon the wet mass of the prey item. For all statistical analyses, we used appropriate transformations if raw data failed to meet assumptions of parametric models. We recognized statistical significance at $P \leq 0.05$ and performed all statistical analyses using SAS (version 9.0; SAS Institute 2000) or the STATISTICA for Windows software package (StatSoft 1998).

To determine whether prey type influenced postfeeding body shape of snakes, 16 snakes $(18.9 \pm 0.47 \mathrm{~g}$; means $\pm \mathrm{SE}$ ) were randomly assigned into the two preytype treatments and each snake was fed a prey item weighing $25.0 \% \pm 0.4 \%$ of its body mass. This relative prey size was selected based on pilot experiments to be small enough that snakes to could consume both prey types, but large enough to substantially impact postfeeding body width and locomotor performance. Maximum snake body width (occurring at the location of the prey item within the snake) was measured $1 \mathrm{~h}$ postfeeding and subsequently at 24-h intervals until body distension due to prey was no longer evident (120 h postingestion). Effect of prey type on body distension was evaluated over time using repeated-measures MANOVA (Profile Analysis).

\section{Experiment I: feeding performance (intra-oral transport)}

We conducted a set of two experiments to examine differences in feeding performance (intra-oral transport time; Cundall and Greene 2000) between snakes fed each of the two prey types. The first experiment used a repeated-measures design to determine if the number of prey consumed differed between prey types across a range of prey sizes (20-65\% of snake body mass). Because this experiment demonstrated that snakes were able to consume much larger (in terms of relative mass) salamanders than fish, a second experiment was designed, wherein snakes were offered only salamanders, to determine the maximum size of salamander that snakes could consume. Finally, data from all successful swallowing events were used to test for differences in intra-oral transport time between the prey types and prey sizes.

In the first experiment, juvenile $N$. fasciata $(n=10 /$ treatment; $9.5 \pm 0.61 \mathrm{~g}$ ) were randomly assigned to a prey size treatment $(20 \%, 35 \%, 50 \%$, or $65 \%$ of the snake's body mass), and each snake was offered $A$. talpoideum and L. marginatus of the assigned size on separate occasions (order randomized). Snakes were offered prey in excess (2-6 individual prey items totaling $>100 \%$ of snake body mass) and no snake consumed all prey offered in any trial. Number of prey consumed was compared between prey types using a Wilcoxon's matched-pairs test separately for each prey size category. In the second experiment, juvenile $N$. fasciata $(n=8-$ $10 /$ treatment; $4.9 \pm 0.26 \mathrm{~g}$ ) were randomly assigned to a prey size treatment $(75 \%, 90 \%, 105 \%$, or $120 \%$ of the snake's body mass), and each snake was offered only $A$. talpoideum.

All feeding trails were conducted within a walk-in environmental chamber at $30^{\circ} \mathrm{C}$. Feeding chambers consisted of $739-\mathrm{mL}$ clear plastic containers to which we added $\sim 10 \mathrm{~mL}$ of water to provide a suitable feeding environment for the watersnakes. Snakes were fasted for $10 \mathrm{~d}$ and allowed to acclimate in feeding chambers within the environmental chamber for $1 \mathrm{~h}$ prior to each trial. Following acclimation, dead, defrosted prey were added to feeding chambers, and a weighted plexiglass sheet was placed over the top of each feeding chamber, allowing detailed feeding observations. During the 1-h trial, the observer recorded the time (nearest second) at which the snake positioned the prey into swallowing position (prey position aligned with the jaws and commencement of "jaw walking") and the time at first tongue flick after swallowing. Intra-oral transport time was defined as the time elapsed between these two events (Krause and Burghardt 2001). If, after $1 \mathrm{~h}$, any snake was still in the process of swallowing a prey item, that individual was not disturbed and was allowed to continue until it either successfully swallowed the meal or regurgitated and discontinued contact with the prey item.

Effects of prey type and prey size (relative mass) on intra-oral transport time were determined using a twofactor analysis of variance (ANOVA) on log-transformed transport times within prey size treatments where both prey types were represented by more than one successful swallowing event (20\% and $35 \%$ of snake body mass). In cases where individual snakes consumed more than one prey item of a given prey type within a size category, the mean transport time was used to avoid pseudo-replication.

\section{Experiment II: digestive metabolism}

A repeated-measures experiment was used to compare metabolic responses of 11 juvenile $N$. fasciata fed salamanders and fish. We modified methods from Hopkins et al. (2004) to measure (1) standard metabolic rate (SMR; the metabolic rate of a resting, postabsorptive ectotherm at a specified temperature during the inactive phase of its circadian cycle; Bennett and Dawson 1976), (2) specific dynamic action (SDA; the increased energy expenditure associated with digestion, 
assimilation, and biosynthesis; Kleiber 1975) after the snake had eaten a Lepomis marginatus of $25 \%$ of the snake's body mass, and (3) SDA after it had eaten an $A$. talpoideum of $25 \%$ of the snake's body mass. Juvenile $N$. fasciata spanning a narrow range of body masses (15.92-22.71 g) were tested to minimize the confounding effects of allometric relationships between mass and metabolic rate. Prior to respirometry trials, snakes were fasted for $10 \mathrm{~d}$ to ensure complete absorption of previous meals. Snakes were then placed in individual chambers (1-L Erlenmeyer flasks) within an environmental chamber $\left(25^{\circ} \mathrm{C}\right.$, constant dark), within which all metabolic measurements were taken. A $20-\mathrm{mL}$ plastic sample bottle was affixed to the bottom of the flask with Velcro to provide water to snakes throughout the experiment.

Metabolic rate was determined indirectly as $\mathrm{O}_{2}$ consumption (adjusted for temperature and pressure) by connecting each chamber to a computer-controlled, closed-system respirometer (Micro Oxymax, Columbus Instruments, Columbus, Ohio, USA). $\mathrm{O}_{2}$ consumption was measured every $48 \mathrm{~min}$ for the first $48 \mathrm{~h}$ to calculate SMR. After every fourth sample, chambers were refreshed with ambient air equaling four times the headspace of each chamber. Following SMR measurements, snakes were removed from the environmental chamber and fed one A. talpoideum or L. marginatus (order determined randomly) equal to $\sim 25 \%$ (24.94\% \pm $0.14 \%$ ) of the snake's body mass. Snakes were then returned to the environmental chamber and respirometry measurements were resumed for the following $144 \mathrm{~h}$ to calculate SDA parameters. During SDA trials, $\mathrm{O}_{2}$ consumption was measured every 36 min with longer intervals (120 $\mathrm{min})$ every third sample to accommodate refreshing of chambers with ambient air. At the midpoint of the SDA trial, snakes were removed, chambers cleaned, and instrumentation recalibrated. Following termination of each snake's first SDA trial, the snake was returned to its cage, where it was fed again, fasted for $10 \mathrm{~d}$, and then started on its second SMR and SDA trial, during which it was fed the second prey type.

Snake SMR was estimated by calculating the mean of the lowest quartile of the $\mathrm{O}_{2}$ measurements obtained for each snake during the 48-h SMR trial (Hopkins et al. 2004). To estimate SDA from postprandial respiration measurements, a two-part smoothing technique was used to remove the effects of spontaneous snake activity on $\mathrm{O}_{2}$ consumption. The smoothing technique used a moving central minimum of three values, followed by a moving central median of 11 measurements (Hopkins et al. 2004). Energy allocated to SMR during digestion was estimated by extrapolating SMR measured before feeding over the digestive period. The integrated $V \mathrm{O}_{2}$ (volume of oxygen) allocated to SMR was then subtracted from the integrated area under each smoothed postprandial curve to calculate the oxygen consumed to support SDA. Additionally, peak post- prandial $\mathrm{O}_{2}$ consumption, digestive scope (peak $\mathrm{O}_{2} /$ $\mathrm{SMR}$ ), time to peak $\mathrm{O}_{2}$, time to $50 \%$ decrease from peak, and time to $75 \%$ decrease from peak were calculated for each snake. SDA was converted to energetic equivalents using a conversion factor of 19.8 $\mathrm{J} / \mathrm{mL} \mathrm{O}_{2}$ (Secor and Diamond 2000), and the cost of digestion (SDA coefficient) was calculated as a percentage of total ingested energy allocated to the SDA response. Because individual snakes received both prey type treatments, individual was used as a blocking factor in a multivariate analysis of variance (MANOVA) to test for effects of prey type on SDA parameters. Because preliminary analyses revealed no overall mass effect $\left(F_{8,2}\right.$ $=1.04, P=0.576$ ), body mass was not included as a covariate in the statistical model.

\section{Experiment III: post-feeding locomotor performance}

A repeated-measures design was used to compare the effects of prey type on locomotor behavior of snakes fed salamanders and fish. Maximum crawling speed was selected as our measure of locomotor performance because watersnakes frequent terrestrial wetland edges while basking to aid digestion. Moreover, within aquatic habitats, N. fasciata are most abundant in shallow, heavily vegetated wetlands (Gibbons and Dorcas 2004; J. D. Willson, unpublished data). In such areas, locomotion is likely more akin to crawling than swimming. Sixteen juvenile N. fasciata $(18.9 \pm 0.47 \mathrm{~g})$ were randomly divided between fish and salamander treatments, and their maximum crawling speed was measured before feeding, immediately post-feeding, and subsequently at several time points during digestion using methods similar to those of Winne and Hopkins (2006). Throughout the experiment, snakes were housed at $28^{\circ} \mathrm{C}$ within an environmental chamber, but locomotor trials were conducted within a temperature-controlled $\left(21.0-22.8^{\circ} \mathrm{C}\right)$ laboratory.

Maximum crawling velocity for each snake was determined using a $2.3-\mathrm{m}$ linear sprint track lined with pairs of photocells projecting infrared beams at $10 \mathrm{~cm}$ intervals interfaced with a laptop computer (Columbus Instruments, Columbus, Ohio, USA; described in detail in Holem et al. 2006). The racetrack was lined with plastic carpet to maximize crawling performance (Winne and Hopkins 2006). Prior to the experiment, snakes were fasted for $10 \mathrm{~d}$ and conditioned to the track by racing them twice in succession $48 \mathrm{~h}$ prior to the start of the experiment. Subsequently, snakes were raced twice in succession at six time intervals: $18 \mathrm{~h}$ before feeding and $1 \mathrm{~h}, 24 \mathrm{~h}, 48 \mathrm{~h}, 72 \mathrm{~h}, 96 \mathrm{~h}$, and $120 \mathrm{~h}$ after consuming a L. marginatus or A. talpoideum equal to $25.0 \% \pm 0.4 \%$ of the snake's body mass.

Prior to beginning each trial, individual snakes were placed in a box attached to the starting point of the track and left undisturbed for approximately one minute. A gate separating the start box from the sprint track was then lifted, and the snake was chased by hand down the track by lightly touching the snake's tail at 

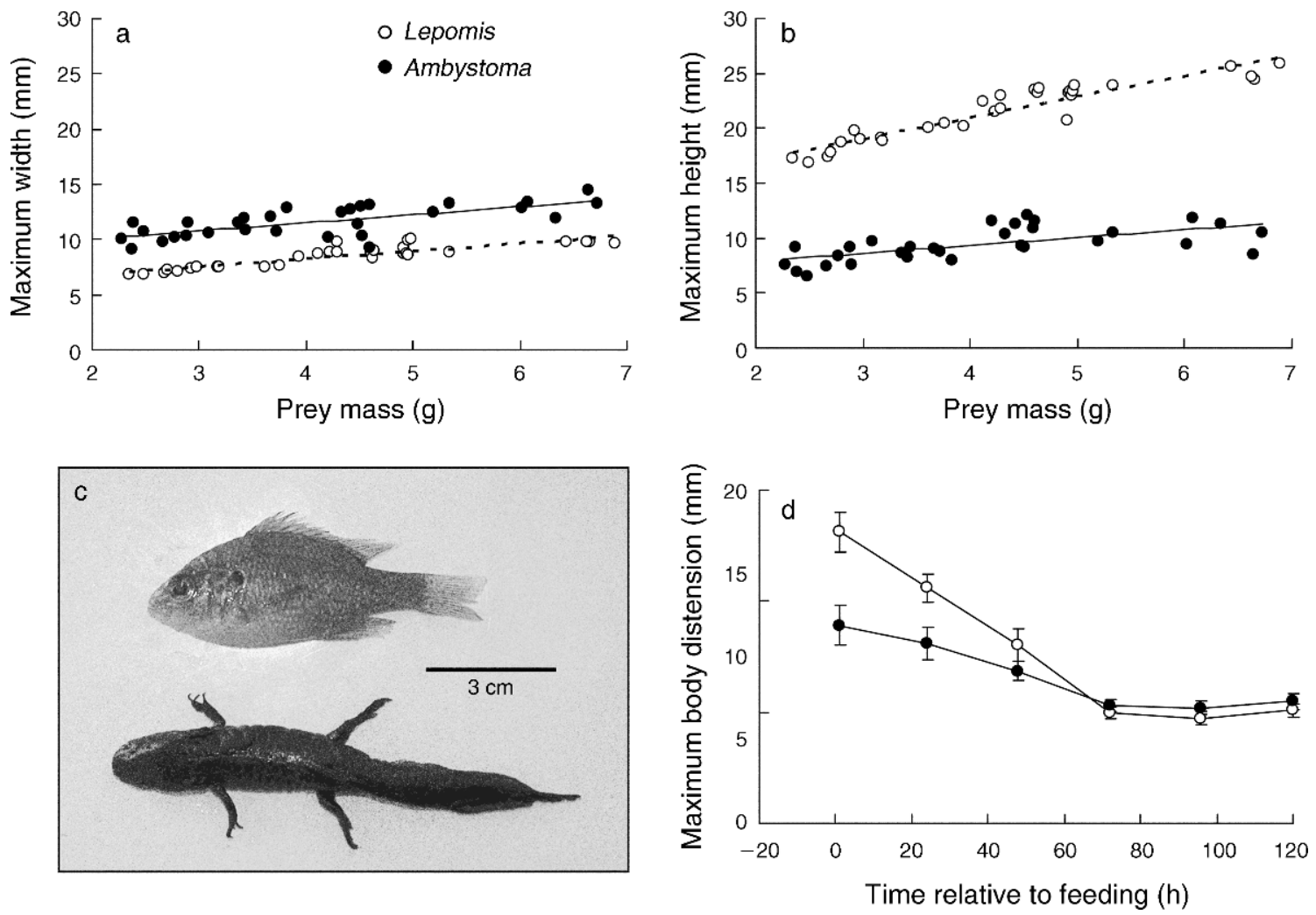

FIG. 1. Characteristics of two prey species of the generalist predator, the banded watersnake (Nerodia fasciata). Shown are differences in body shape between paedomorphic mole salamanders Ambystoma talpoideum and dollar sunfish Lepomis marginatus, including (a) maximum width and (b) maximum height in relation to body mass. Maximum body dimensions were at the head in $A$. talpoideum and just anterior to the dorsal fin in L. marginatus. (c) Morphological differences between the two prey types are shown in a photograph depicting individuals of equal mass. (d) Post-ingestion differences between the prey types are evident in a time series of body distension (maximum body width $\pm \mathrm{SE}$ ) in snakes fed prey weighing $25 \%$ of snake body mass.

approximately one second intervals to prompt a flight response (Huey et al. 1989, Winne and Hopkins 2006). The time it took for each individual to crawl $60 \mathrm{~cm}$ was calculated for each $60-\mathrm{cm}$ segment of the track, and the single fastest velocity for each individual was used as an estimate of maximum locomotor performance in statistical comparisons. Effect of prey type on post-feeding maximum sprint velocity was evaluated using repeatedmeasures MANOVA (Profile Analysis). Because preliminary analyses revealed no overall effect of snake body mass $\left(F_{1,13}=0.19, P=0.674\right)$, snake mass was not included as a covariate in the statistical model.

\section{RESUlts}

\section{Prey shape and nutritional composition}

Substantial differences in shape were evident between salamanders and fish (Fig. 1). Although A. talpoideum had a slightly larger maximum body width than $L$. marginatus at a given mass $\left(F_{1,57}=293.7, P<0.001\right.$; Fig. 1a), L. marginatus had substantially greater maximum height than $A$. talpoideum at all body sizes $\left(F_{1,57}=1224.9, P<0.001\right.$; Fig. $\left.1 b\right)$. Snakes generally oriented L. marginatus laterally (side down) during swallowing, whereas A. talpoideum were generally consumed dorsoventrally (vent down). Thus, the most meaningful comparison of shape between the prey types is between body width in A. talpoideum and body height in L. marginatus. Even considering the differences in swallowing position, however, L. marginatus had a substantially greater maximum body dimension than $A$. talpoideum (L. marginatus height vs. A. talpoideum width; $F_{1,57}=1200.03, P<0.001$; Fig. 1). Additionally, although we considered only dead prey, it is important to consider that dorsal spines, which would be erected by live Lepomis in response to attack by a predator, would further increase body height in L. marginatus. Following feeding, snakes fed L. marginatus exhibited much greater body distension (maximum body width) than those fed an equivalently sized $A$. talpoideum (timeby-prey type interaction, $F_{5,70}=8.35, P=0.003$; Fig. $1 \mathrm{~d}$ ).

Overall, nutritional composition was similar between the two prey types (Table 1). Energy content per unit mass and lipid content did not differ between the prey types. Although L. marginatus had a slightly (2.4\%) higher protein content per unit mass than A.talpoideum, the most substantial difference between the prey types 
TABle 1. Nutritional composition (mean $\pm \mathrm{SE}$ ) relative to prey wet mass of Ambystoma talpoideum and Lepomis marginatus.

\begin{tabular}{lrrrr}
\hline \hline \multicolumn{1}{c}{ Component } & Ambystoma & \multicolumn{1}{c}{ Lepomis } & \multicolumn{1}{c}{$F_{1,5}$} & \multicolumn{1}{c}{$P$} \\
\hline $\mathrm{H}_{2} \mathrm{O}(\%)$ & $81.33 \pm 0.32$ & $75.93 \pm 0.42$ & 59.59 & $<\mathbf{0 . 0 0 1}$ \\
Protein $(\%)$ & $12.22 \pm 0.35$ & $14.62 \pm 0.37$ & 15.17 & $\mathbf{0 . 0 1 1}$ \\
Lipid $(\%)$ & $2.23 \pm 0.18$ & $2.37 \pm 0.25$ & 0.11 & 0.749 \\
Energy content $(\mathrm{kJ} / \mathrm{g})$ & $4.06 \pm 0.12$ & $4.63 \pm 0.14$ & 3.59 & 0.117 \\
\hline
\end{tabular}

Note: Significant differences between prey types (ANCOVA) are indicated in boldface.

was in water content, with A. talpoideum having $6 \%$ greater water content than L. marginatus.

\section{Feeding performance (intra-oral transport)}

Snakes showed substantial differences in feeding performance between the two prey types. Although the maximum size of L. marginatus consumed by a juvenile $N$. fasciata was $50 \%$ of the snake's body mass, three of 10 snakes were able to consume $A$. talpoideum equal to $105 \%$ of the snake's body mass (Fig. 2). Within the smallest prey size category ( $20 \%$ of snake body mass), snakes consumed an average of 1.5 prey items, regardless of prey type (Wilcoxon's matched pairs test; $Z=1.60, P=0.109)$. However, snakes consumed significantly more $A$. talpoideum than L. marginatus within all larger prey size categories tested: $35 \%$ of snake body mass $(Z=2.20, P=0.028), 50 \%$ of snake body mass $(Z=2.80, P=0.005), 65 \%$ of snake body mass $(Z=$ 2.67, $P=0.007)$.

Within prey size categories where both prey types could be consumed ( $20 \%$ and $35 \%$ of snake body mass), prey type had a significant effect on intra-oral transport time $\left(F_{1,30}=120.60, P<0.001\right.$; Fig. 3$)$. At $35 \%$ of snake body mass, mean transport time for L. marginatus (20.6 min) was nearly 15 times higher than that of $A$. talpoideum (1.5 min). Even transport time of $A$. talpoideum of $105 \%$ of snake body mass $(9.0 \mathrm{~min})$ was only half as long as that of L. marginatus of $35 \%$ of snake body mass (20.6 min). Prey size also had a significant effect on intra-oral transport time $\left(F_{1,30}=\right.$ 18.2, $P<0.001$ ), with larger prey taking longer to transport in both prey types.

\section{Digestive metabolism}

Juvenile $N$. fasciata weighing $18.47 \pm 0.29 \mathrm{~g}$ had SMRs of $0.66 \pm 0.04 \mathrm{~mL} \mathrm{O}_{2} / \mathrm{h}$, and SMR did not differ between treatments (Table 2). After consuming meals of $25 \%$ of their body mass, snakes exhibited classic SDA response curves (Fig. 4). Overall, SDA curves were similar between the two prey types $\left(F_{8,3}=7.49, P=\right.$ $0.063)$, with only subtle differences in the shapes of the curves (Fig. 4). Individual comparisons revealed no effect of treatment on total $V \mathrm{O}_{2}$ consumed, peak $\mathrm{O}_{2}$, digestive scope, SDA coefficient (proportion of ingested energy allocated to SDA), and time to peak $\mathrm{O}_{2}$ consumption (Table 2). However, treatment did significantly affect time to $50 \%$ and $75 \%$ decrease from peak $\mathrm{O}_{2}$ consumption (Table 2), with snakes fed A. talpoideum declining more steeply towards baseline $\mathrm{O}_{2}$ consumption rate than snakes fed L. marginatus (Fig. 4).

\section{Post-feeding locomotor performance}

Prior to feeding, snakes in both treatment groups exhibited maximum crawling speeds of $\sim 25 \mathrm{~cm} / \mathrm{s}$ (Fig. 5). Following consumption of prey, snakes in both treatment groups exhibited significant reductions in

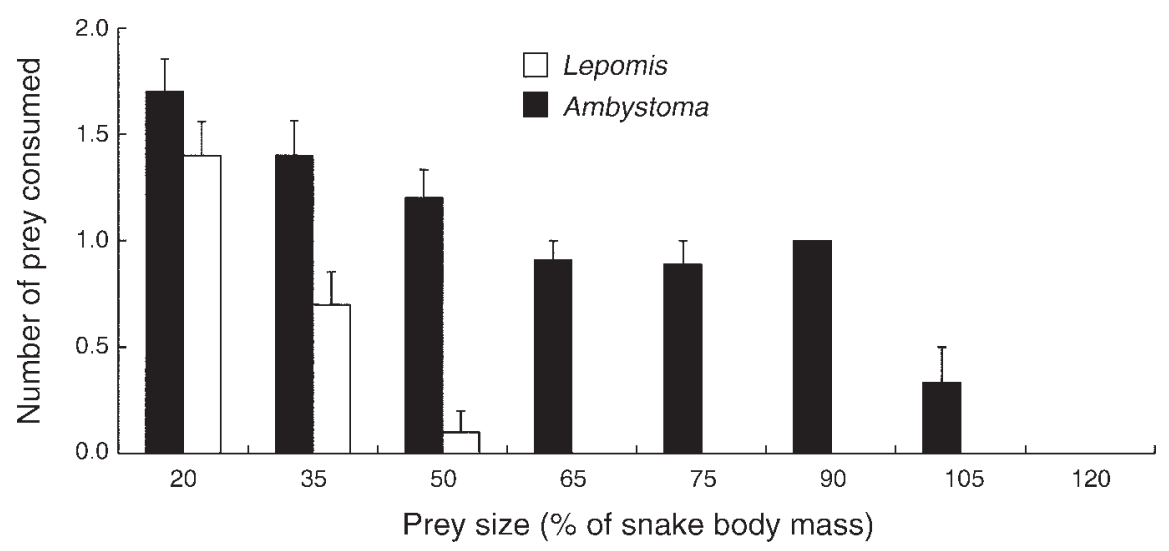

FIG. 2. Number of prey consumed (mean + SE) by juvenile Nerodia fasciata fed Ambystoma talpoideum or Lepomis marginatus of varying sizes. For prey sizes between $20 \%$ and $65 \%$ of snake body mass, snakes were offered both A. talpoideum and L. marginatus, on separate occasions. For prey sizes $>65 \%$, snakes were offered only A. talpoideum of larger size. In all cases snakes were offered prey in excess, and no snake consumed all prey offered. 


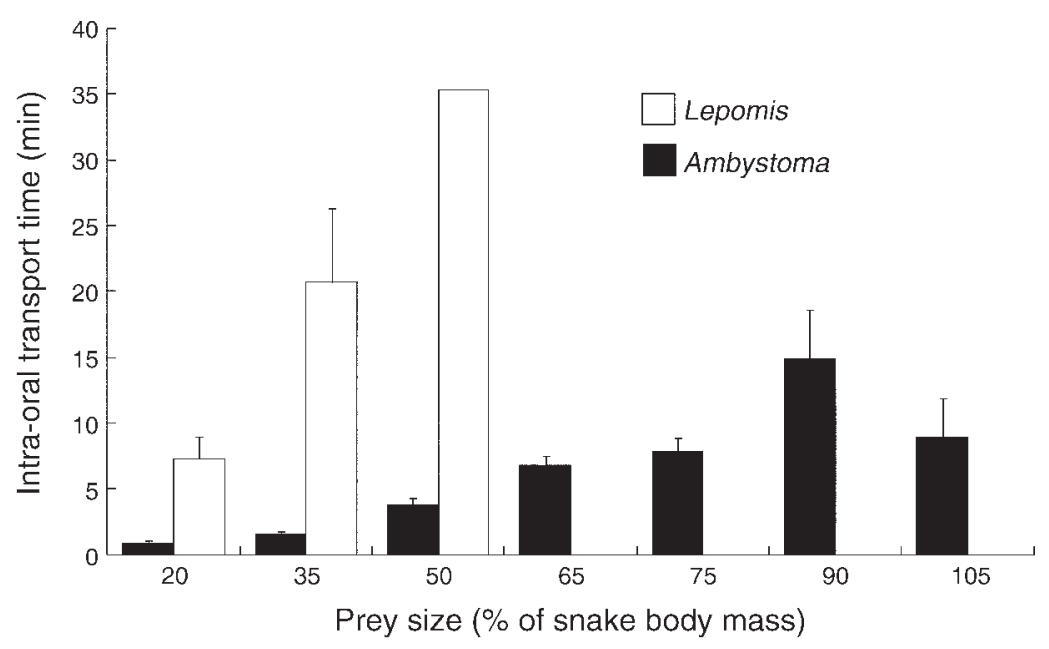

FIG. 3. Mean (+SE) intra-oral transport times (time from commencement of jaw walking to first tongue flick after swallowing) of juvenile Nerodia fasciata fed Ambystoma talpoideum or Lepomis marginatus of varying sizes. Lack of error bars for Lepomis in the $50 \%$ size category reflects the fact that only one snake consumed a Lepomis of that size.

maximum sprint speed (time, $F_{6,84}=16.71, P<0.001$ ). This reduction, however, was much more pronounced in snakes fed L. marginatus than in snakes fed $A$. talpoideum (time-by-prey type interaction, $F_{6,84}=2.67$, $P=0.020)$. When tested $1 \mathrm{~h}$ post-feeding, snakes fed $L$. marginatus displayed an average maximum sprint velocity of $13 \mathrm{~cm} / \mathrm{s}$, a reduction of nearly $45 \%$ from pre-feeding speed, whereas snakes fed A. talpoideum displayed a maximum sprint velocity of $21 \mathrm{~cm} / \mathrm{s}$, a reduction of only $23 \%$ from pre-feeding speed. Snakes gradually increased in mean sprint velocity during digestion. However, snakes that had consumed $L$. marginatus did not attain preprandial crawling velocities until $\sim 100 \mathrm{~h}$ after feeding.

\section{DisCUSSION}

Our results suggest that the shape of aquatic salamanders (e.g., Ambystoma talpoideum) make them a more desirable prey for juvenile watersnakes than centrarchid fish (e.g., Lepomis marginatus). Energetic content per unit prey mass did not differ between the prey types and only slight differences existed in nutritional content; Lepomis was $2.4 \%$ higher in protein content than Ambystoma. However, the slight advantage of Lepomis in terms of protein content was offset by the fact that juvenile $N$. fasciata were able to consume much larger Ambystoma than Lepomis and consumed more Ambystoma at sizes where both prey types could be consumed. Although cost of digestion (SDA response) was similar between the prey types, likely reflecting their similar nutritional composition, other costs associated with consumption were higher for Lepomis than for Ambystoma. Specifically, Lepomis induced greater postprandial body distension in snakes than did Ambystoma, resulting in severely impaired locomotor performance. These differences highlight the complexity of evaluating prey quality for generalist predators and highlight the advantages of elongate prey (such as amphibians) for snakes.

TABLE 2. Metabolic parameters (mean $\pm \mathrm{SE}$ ) of Nerodia fasciata fed Ambystoma talpoideum and Lepomis marginatus equal to $25 \%$ of snake body mass at $25^{\circ} \mathrm{C}$.

\begin{tabular}{|c|c|c|c|c|}
\hline Parameter measured (units) & Ambystoma & Lepomis & $F_{1,10}$ & $P$ \\
\hline$N$ (number of snakes fed) & 11 & 11 & & \\
\hline Mass (g) & $18.63 \pm 0.49$ & $18.31 \pm 0.34$ & & \\
\hline $\operatorname{SMR}\left(\mathrm{mL} \mathrm{O}_{2} / \mathrm{h}\right)$ & $0.65 \pm 0.06$ & $0.67 \pm 0.06$ & 0.59 & 0.46 \\
\hline Peak $\mathrm{O}_{2}$ rate $\left(\mathrm{mL} \mathrm{O}_{2} / \mathrm{h}\right)$ & $4.00 \pm 0.14$ & $4.02 \pm 0.09$ & 0.00 & 0.98 \\
\hline Digestive scope (peak $\mathrm{O}_{2} / \mathrm{SMR}$ ) & $6.53 \pm 0.40$ & $6.54 \pm 0.65$ & 3.23 & 0.10 \\
\hline Time to peak $\mathrm{O}_{2}(\mathrm{~h})$ & $31.75 \pm 2.91$ & $24.91 \pm 2.00$ & 2.22 & 0.17 \\
\hline Time to $50 \%$ decrease from peak $(\mathrm{h})$ & $68.27 \pm 1.53$ & $74.33 \pm 2.19$ & 5.77 & 0.04 \\
\hline Time to $75 \%$ decrease from peak (h) & $81.21 \pm 1.72$ & $95.94 \pm 5.95$ & 5.66 & 0.04 \\
\hline \multicolumn{5}{|l|}{ SDA } \\
\hline Total $\mathrm{O}_{2}$ consumed $(\mathrm{mL})$ & $229.54 \pm 7.01$ & $242.67 \pm 8.88$ & 0.49 & 0.50 \\
\hline Total energy expended $(\mathrm{kJ})$ & $4.54 \pm 0.18$ & $4.80 \pm 0.18$ & & \\
\hline SDA coefficient ( $\%$ ingested energy utilized) & $23.83 \pm 0.47$ & $22.98 \pm 0.66$ & 0.03 & 0.87 \\
\hline
\end{tabular}

Notes: Significant differences between prey types (MANOVA; individual as blocking factor) are indicated in boldface. Abbreviations are: SMR, standard metabolic rate; and SDA, specific dynamic action. 


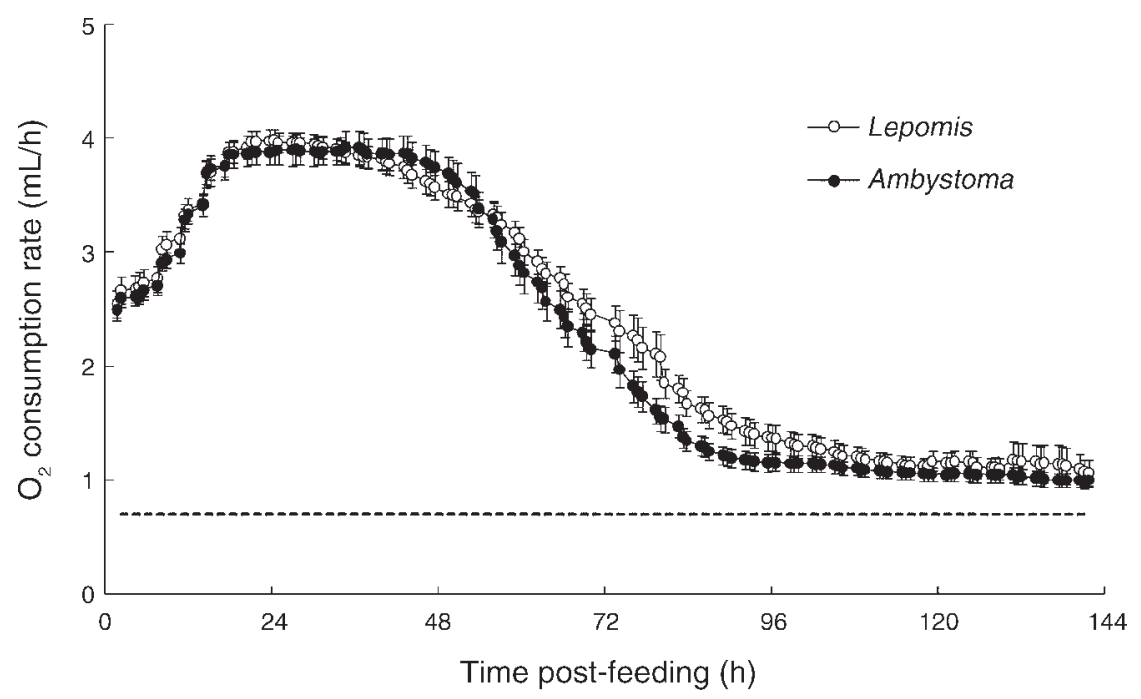

FIG. 4. Oxygen consumption (mean $\pm \mathrm{SE}$ ) by juvenile Nerodia fasciata fed an Ambystoma talpoideum or Lepomis marginatus equal to $25 \%$ of the snake's body mass at $25^{\circ} \mathrm{C}$. The dashed line represents Nerodia fasciata's standard metabolic rate (SMR).

\section{Feeding performance (intra-oral transport)}

Although snakes are well known for their ability to consume massive meals relative to their body size, our understanding of how prey shape contributes to feeding performance is limited (but see Mori 1991, 1997, Kley and Brainerd 2002, Vincent et al. 2006). We found that prey shape was extremely important in determining the maximum size of prey that could be consumed by snakes; the maximum size of Ambystoma that snakes could consume ( $105 \%$ of snake mass) was over twice the maximum size of Lepomis (50\% of snake mass). This result corroborates the findings of Vincent et al. (2006), who concluded that prey with greater maximum dimensions were more difficult for snakes to consume than more elongate prey. Interestingly, the upper size of Ambystoma that snakes were able to consume was apparently not dictated by gape limitation. In fact, three snakes attempting to swallow very large Ambystoma ( $105 \%$ or $120 \%$ of their body mass) all managed to get well past the widest point of the prey item (head) before regurgitating. This observation suggests that snakes may be limited by the volume of their stomach, rather than their gape, when consuming elongate prey such as $A$. talpoideum. Alternatively, these large prey may have filled the snake's body cavity so completely that cardiovascular or respiratory function would have been impaired had the snake not regurgitated. Other authors have noted that elongate, but massive, prey represent the ideal prey shape for snakes and it has been suggested that a switch to elongate prey was a precursor to the success, and subsequent diversification, of ancestral snakes (Greene 1983). Our results support this conclusion by demonstrating that, for snakes, feeding on large, elongate prey can alleviate the constraints of gape limitation.
We also observed striking differences in intra-oral transport time between the two prey types. Transport time was always longer for Lepomis, and even Ambystoma of over $100 \%$ of snake body mass took less than half as long to transport as Lepomis weighing 35\% of snake body mass. These results confirm the findings of Vincent et al. (2006) that prey shape, independent of prey mass, can be an important determinant of snake feeding performance. Vincent et al. (2006) suggested that wide or bulky prey may interfere with a snake's ability to use anterior vertebral bending to transport prey past the jaws. It is likely that the narrow, high shape and stiff structure of Lepomis contributed to the longer transport times we observed by forcing snakes to rely primarily on jaw protractions to transport fish (Kley and Brainerd 2002). Alternatively, it is likely that the elongate shape of Ambystoma placed the anterior portion of the prey item far enough past the cranium

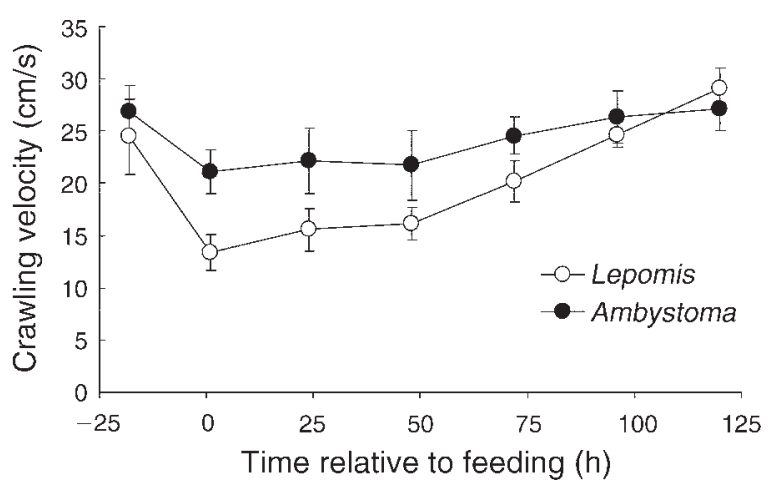

FIG. 5. Post-feeding locomotor impairment of juvenile Nerodia fasciata fed Ambystoma talpoideum and Lepomis marginatus. Plots represent maximum crawling speeds (mean $\pm \mathrm{SE}$ ) over a $60-\mathrm{cm}$ interval $18 \mathrm{~h}$ prior to feeding and $1 \mathrm{~h}, 24 \mathrm{~h}$, $48 \mathrm{~h}, 72 \mathrm{~h}, 96 \mathrm{~h}$, and $120 \mathrm{~h}$ after consuming prey equal to $25 \%$ of the snake's body mass. 
to permit the use of concertina-like movements of the anterior portion of the snake's trunk to aid in intra-oral transport (Cundall and Greene 2000, Kley and Brainerd 2002), resulting in rapid transport times, even for very large prey. Further, although we tested only dead prey, transport of live Lepomis would likely be further hindered by the erection of sharp dorsal spines, increasing body height of Lepomis relative to Ambystoma. Although the energetic cost of prey transport and swallowing in snakes is likely small in relation to the net energy gained from the meal (Feder and Arnold 1982, Cruz-Neto et al. 2001), differences in transport time are important. Increased prey handling time may increase predation risk, especially in juvenile snakes (Arnold 1993, Vincent et al. 2006). Many animals, including snakes, are known to make foraging vs. risk decisions (Sih 1992, Lima 1998, Aubret et al. 2007). Thus, snakes may avoid prey that incur an increased risk of predation. Alternatively, snakes inhabiting habitats where the only prey available require lengthy transport times (e.g., permanent wetlands) may be subject to elevated levels of predation.

\section{Cost of digestion}

Previous studies suggest that nutritional composition, particularly protein content, is the primary driver of the SDA response in ectotherms (McCue et al. 2005). This conclusion is based primarily on observations that SDA response correlates strongly with protein content of meals (Hailey 1998). Moreover, inhibition of protein synthesis has been shown to disable the SDA response in both fish (Brown and Cameron 1991a,b) and snakes (McCue et al. 2005). However, little is known about the effects of prey shape or other morphological attributes on digestive physiology, and few studies have compared SDA responses of ectotherms fed natural prey types that are similar in nutritional composition, but different in morphology.

Although Ambystoma and Lepomis are similar in nutritional composition, we hypothesized that Ambystoma would be less costly to digest than Lepomis because Ambystoma lack scales, spiny fin rays, or other presumably difficult to digest materials. Surprisingly, we found that SDA profiles were similar for snakes digesting the two prey types. This result is consistent with the general conclusion that nutritional composition of prey is the strongest determinant of SDA in snakes. However, we did detect slight differences between the prey types in the shapes of the SDA curves (time to $50 \%$ and $75 \%$ decrease from peak $\mathrm{O}_{2}$ consumption), with digestion being completed slightly more rapidly in snakes fed $A$. talpoideum. Although the biological relevance of these slight differences is debatable, it is possible that the slightly faster digestion of A. talpoideum, combined with the lack of post-feeding locomotor impairment, could allow for a greater turnover rate of prey items, and consequently faster growth of snakes.

\section{Post-feeding locomotor performance}

Snakes with slim, elongate morphology generally exhibit faster maximum crawling speeds than those with stouter body forms (Ruben 1977, Shine and Shetty 2001, Shine et al. 2003). It follows that changes in relative snake mass and body width have direct effects on locomotor performance. For example, female snakes suffer reduced locomotor performance during pregnancy, due in part to the added burden of offspring (Seigel et al. 1987, Winne and Hopkins 2006). Likewise, consuming a large meal comes at a cost to locomotor performance, both on land (Garland and Arnold 1983, Mehta 2006) and in the water (Shine and Shetty 2001). For example, Ford and Shuttlesworth (1986) found that checkered garter snakes (Thamnophis marcianus) fed large meals exhibited reduced maximum sprint speed, average crawling speed, and endurance. However, our study is the first to report differences in locomotor performance associated with differences in prey shape, independent of prey mass. We found that snakes fed Lepomis exhibited much more impaired crawling speeds than those fed Ambystoma. Our results are not unexpected given that Lepomis induced a much greater distortion of normal body form than did Ambystoma.

Presumably, reduction in sprint speed is associated with increased exposure to predators and subsequent reduction in survivorship (Shine 1980, Jayne and Bennett 1990, Husak 2006a,b). Thus, all else being equal, juvenile $N$. fasciata feeding on centrarchid fish could experience reduced survivorship compared to those feeding on aquatic salamanders. Additionally, impaired locomotor ability may reduce snake's abilities to procure sequential prey items, ultimately reducing individual growth rates, slowing time to maturity, and retarding population growth.

\section{Conclusions}

Our results suggest that using resource availability as an index of habitat quality for generalist predators is complex, requiring consideration of more than simple prey abundance or even nutritional composition. Although the prey types we considered were similar in size and nutritional composition, differences in shape lead to substantial differences in overall prey quality. Further, the prey we considered are characteristic of different aquatic habitat types. Whereas centrarchid fish are abundant in permanent water bodies, paedomorphic salamanders are the dominant prey type (by biomass) within fishless, often temporary, wetlands (Appendix).

In South Carolina, N. fasciata are abundant in fishless wetlands, despite the fact that they experience precipitous declines in these habitats during periodic extreme droughts (Seigel et al. 1995, Willson et al. 2006). However, following drought-induced population declines, N. fasciata populations rebound rapidly, driven by high fecundity of surviving females and subsequent rapid growth to maturity of juveniles (Winne 2008). This rapid recovery may be fueled in part by the remarkable 
productivity of amphibians in these habitats. Moreover, the ability of snakes to consume very large salamanders with relatively minor impediments to locomotor performance, may facilitate the high abundances and rapid individual and population growth of $N$. fasciata observed in fishless wetland habitats (Winne 2008). Conversely, consuming centrarchid fish imposes constraints on maximum prey size and induces lengthened transport times and impaired crawling speeds that presumably increase a snake's risk of predation. Thus, in more permanent aquatic habitats, juvenile snakes may be forced to either persist on a lower quality diet or resort to alternative prey types. Alternative prey could include those that are abundant but so small that they must be captured in large quantities to meet energetic demands (e.g., Gambusia and Fundulus) or those that are large but less abundant (e.g., adult anurans; see Appendix). In permanent cypress swamp habitats in Louisiana, juvenile $N$. fasciata fed predominantly on Gambusia, while adults fed predominantly on frogs (Mushinsky et al. 1982), with neither demographic preying extensively on centrarchid fish, despite their availability (Mushinsky and Hebrard 1977). Thus, the abundance of amphibians within fishless wetlands may make these habitats particularly important for aquatic snakes.

Our results highlight the importance of considering various aspects of prey quality when attempting to use prey abundance as an indicator of overall habitat suitability. When attempting to assess prey quality, the energetic and nutritional content of potential prey must be measured against the costs associated with prey ingestion, transport, swallowing, and processing. Although we have focused on snakes, our findings apply to many groups of organisms, especially predators that do not reduce prey size by mastication and thus are limited in the sizes and shapes of prey they can consume. Such predators include amphibians, most lizards and fishes, some birds, and a wide variety of aquatic invertebrates. For such organisms, variation in prey morphology, including shape, may lead to substantial costs in terms of handling and processing time, increased predation risk, or post-feeding performance.

\section{ACKNOWLEDGMENTS}

We thank J. Whitfield Gibbons for his support and encouragement. Additionally, we thank Andrew Durso and Evan Eskew for collecting data on prey availability and Sarah DuRant, Brian Todd, and Christopher Winne for advice on design and statistical analyses. Michael Dorcas, Sarah DuRant, J. Whitfield Gibbons, and Jerry Husak provided insightful comments on the manuscript. Snakes and prey were collected under South Carolina Department of Natural Resources scientific collection permits (G-05-03), and procedures used in the study were approved by the University of Georgia animal care and use committee (AUP A2005-10102-c2). This research was supported by the National Science Foundation (Graduate Research Fellowship to J. D. Willson and I0B-0615361 to W. A. Hopkins), a Grant-in-aid of Research to J. D. Willson from the Society for Integrative and Comparative Biology, and the Department of Energy under Award Number DE-FC-09075R22506.

\section{Literature Cited}

Arnold, S. J. 1993. Foraging theory and prey-size-predator-size relations in snakes. Pages $87-115$ in R. A. Seigel and J. T. Collins, editors. Snakes: ecology and behavior. McGrawHill, New York, New York, USA.

Aubret, F., X. Bonnet, and D. Bradshaw. 2007. Food versus risk: foraging decision in young Tiger snakes, Notechis scutatus. Amphibia-Reptilia 28:304-308.

Bennett, A. F., and W. R. Dawson. 1976. Metabolism. Pages 123-223 in C. Gans, editor. Biology of the reptilia. Volume 5. Physiology A. Academic Press, New York, New York, USA.

Brown, C. R., and J. N. Cameron. 1991a. The induction of specific dynamic action in the channel catfish by infusion of essential amino acids. Physiological Zoology 64:276-297.

Brown, C. R., and J. N. Cameron. 1991b. The relationship between specific dynamic action (SDA) and protein synthesis rates in the channel catfish. Physiological Zoology 64:298309.

Crowder, L. B., and W. E. Cooper. 1982. Habitat structural complexity and the interaction between bluegills and their prey. Ecology 63:1802-1813.

Cruz-Neto, A. P., D. V. Andrade, and A. S. Abe. 2001. Energetic and physiological correlates of prey handling and ingestion in lizards and snakes. Comparative Biochemistry and Physiology Part A, Molecular and Integrative Physiology 128:515-533.

Cundall, D. 1987. Functional ecology. Pages 253-301 in R. A. Seigel, J. T. Collins, and S. S. Novak, editors. Snakes: ecology and evolutionary biology. Blackburn Press, Caldwell, New Jersey, USA.

Cundall, D., and H. W. Greene. 2000. Feeding in snakes. Pages 293-333 in K. Schwenk, editor. Feeding: form, function, and evolution in tetrapod vertebrates. Academic Press, London, UK.

Feder, M. E., and S. J. Arnold. 1982. Anaerobic metabolism and behavior during predatory encounters between snakes (Thamnophis elegans) and salamanders (Plethodon jordani). Oecologia 53:93-97.

Ford, N. B., and G. A. Shuttlesworth. 1986. Effects of variation in food intake on locomotory performance of juvenile garter snakes. Copeia 1986:999-1001.

Garland, T., and S. J. Arnold. 1983. Effects of a full stomach on locomotory performance of juvenile garter snakes (Thamnophis elegans). Copeia 1983:1092-1096.

Gibbons, J. W., and M. E. Dorcas. 2004. North American watersnakes: a natural history. University of Oklahoma Press, Norman, Oklahoma, USA.

Greene, H. W. 1983. Dietary correlates of the origin and radiation of snakes. American Zoologist 23:431-441.

Hailey, A. 1998. The specific dynamic action of the omnivorous tortoise Kinixys spekii in relation to diet, feeding pattern, and gut passage. Physiological Zoology 71:57-66.

Holem, R. R., W. A. Hopkins, and L. G. Talent. 2006. Effect of acute exposure to malathion and lead on sprint performance of the western fence lizard (Sceloporus occidentalis). Archives of Environmental Contamination and Toxicology 51:111116.

Hopkins, W. A., J. H. Roe, T. Philippi, and J. D. Congdon. 2004. Standard and digestive metabolism in the banded water snake, Nerodia fasciata fasciata. Comparative Biochemistry and Physiology Part A, Molecular and Integrative Physiology 137:141-149.

Huey, R. B., P. H. Niewiarowski, J. Kaufmann, and J. C. Herron. 1989. Thermal biology of nocturnal ectotherms: is sprint speed of geckos maximal at low body temperatures? Physiological Zoology 62:488-504. 
Husak, J. F. 2006a. Does speed help you survive? A test with collared lizards of different ages. Functional Ecology 20:174179.

Husak, J. F. 2006b. Does survival depend on how fast you can run or how fast you do run? Functional Ecology 20:10801086.

Jayne, B. C., and A. F. Bennett. 1990. Selection on locomotor performance in a natural population of garter snakes. Evolution 44:1204-1229.

Kitaysky, A. S., E. V. Kitaiskaia, J. F. Piatt, and J. C. Wingfield. 2006. A mechanistic link between chick diet and decline in seabirds? Proceedings of the Royal Society B 273: 445-450.

Kleiber, M. 1975. The fire of life: an introduction to animal energetics. Krieger, New York, New York, USA.

Kley, N. J., and E. L. Brainerd. 2002. Post-cranial prey transport mechanisms in the black pinesnake, Pituophis melanoleucus lodingi: an x-ray videographic study. Zoology 105:153-164.

Krause, M. A., and G. M. Burghardt. 2001. Neonatal plasticity and adult foraging behavior in garter snakes (Thamnophis sirtalis) from two nearby, but ecologically dissimilar, habitats. Herpetological Monographs 15:100-123.

Lima, S. L. 1998. Stress and decision making under the risk of predation: recent developments from behavioral, reproductive, and ecological perspectives. Advances in the Study of Behavior 27:215-290.

Mayntz, D., S. Toft, and F. Vollrath. 2003. Effects of prey quality and availability on the life history of a trap-building predator. Oikos 101:631-638.

McCue, M. D., A. F. Bennett, and J. W. Hicks. 2005. The effect of meal composition on specific dynamic action in Burmese pythons (Python molurus). Physiological and Biochemical Zoology 78:182-192.

Mehta, R. S. 2006. Meal size effects on antipredator behavior of hatchling trinket snakes, Elaphe helena. Ethology 112:649656.

Mehta, R. S., and G. M. Burghardt. 2008. Contextual flexibility: reassessing the effects of prey size and status on prey restraint behaviour of macrostomate snakes. Ethology 114:133-145.

Mori, A. 1991. Effects of prey size and type on prey-handling behavior in Elaphe quadrivirgata. Journal of Herpetology 25: 160-166.

Mori, A. 1993. Prey handling behavior of neonatal rat snakes, Elaphe taeniura and E. dione (Colubridae). Japanese Journal of Herpetology 15:59-63.

Mori, A. 1996. A comparative study of the development of prey handling behavior in young rat snakes, Elaphe quadrivirgata and E. climacophora. Herpetologica 52:313-322.

Mori, A. 1997. A comparison of predatory behavior of newly hatched Rhabdophis tigrinus (Serpentes: Colubridae) on frogs and fish. Japanese Journal of Herpetology 17:39-45.

Mullin, S. J., and R. J. Cooper. 2000. The foraging ecology of the gray rat snake (Elaphe obsoleta spiloides). II. Influence of habitat structural complexity when searching for arboreal avian prey. Amphibia-Reptilia 21:211-222.

Mushinsky, H. R., and J. J. Hebrard. 1977. Food partitioning by five species of water snakes in Louisiana. Herpetologica 33:162-166.

Mushinsky, H. R., J. J. Hebrard, and D. S. Vodopich. 1982. Ontogeny of water snake foraging ecology. Ecology 63:16241629.

Ruben, J. A. 1977. Morphological correlates of predatory modes in the coachwhip (Masticophis flagellum) and rosy boa (Lichanura roseofusca). Herpetologica 33:1-6.

SAS Institute. 2000. SAS. Version 9.0. SAS Institute, Cary, North Carolina, USA.

Secor, S. M., and J. M. Diamond. 2000. Evolution of regulatory responses to feeding in snakes. Physiological and Biochemical Zoology 73:123-141.

Seigel, R. A., J. W. Gibbons, and T. K. Lynch. 1995. Temporal changes in reptile populations: effects of a severe drought on aquatic snakes. Herpetologica 51:424-434.

Seigel, R. A., M. M. Huggins, and N. B. Ford. 1987. Reduction in locomotor ability as a cost of reproduction in gravid snakes. Oecologia 73:481-485.

Shine, R. 1980. Costs of reproduction in reptiles. Oecologia 46: 92-100.

Shine, R., H. G. Cogger, R. R. Reed, S. Shetty, and X. Bonnet. 2003. Aquatic and terrestrial locomotor speeds of amphibious sea-snakes (Serpentes, Laticaudidae). Journal of Zoology 259:261-268.

Shine, R., and S. Shetty. 2001. Moving in two worlds: aquatic and terrestrial locomotion in sea snakes (Laticauda colubrina, Laticaudidae). Journal of Evolutionary Biology 14:338-346.

Sih, A. 1992. Prey uncertainty and the balancing of antipredator and feeding needs. American Naturalist 139:1052-1069.

StatSoft. 1998. STATISTICA for Windows software package. StatSoft, Tulsa, Oklahoma, USA.

Vincent, S. E., B. R. Moon, R. Shine, and A. Herrel. 2006. The functional meaning of "prey size" in water snakes (Nerodia fasciata, Colubridae). Oecologia 147:204-211.

White, T. C. R. 2008. The role of food, weather and climate in limiting the abundance of animals. Biological Reviews 83: 227-248.

Wilder, S. M., and A. L. Rypstra. 2008. Diet quality affects mating behaviour and egg production in a wolf spider. Animal Behaviour 76:439-445.

Willson, J. D., C. T. Winne, M. E. Dorcas, and J. W. Gibbons. 2006. Post-drought responses of semi-aquatic snakes inhabiting an isolated wetland: Insights on different strategies for persistence in a dynamic habitat. Wetlands 26:1071-1078.

Winne, C. T. 2008. Seminatrix pygaea, a model of ecological resilience to dynamic habitats. Dissertation. University of Georgia, Athens, Georgia, USA.

Winne, C. T., and W. A. Hopkins. 2006. Influence of sex and reproductive condition on terrestrial and aquatic locomotor performance in the semi-aquatic snake Seminatrix pygaea. Functional Ecology 20:1054-1061.

\section{APPENDIX}

Availability of prey for juvenile banded watersnakes (Nerodia fasciata) in permanent and periodically dry wetlands in South Carolina, USA (Ecological Archives E092-062-A1). 